\title{
Effect of Ultrasound-Assisted Extraction of Moringa stenopetala Leaves on Bioactive Compounds and Their Antioxidant Activity
}

\author{
Debebe Worku Dadi ${ }^{1,2 *}$, \\ Shimelis Admassu Emire?2, \\ Asfaw Debella Hagos ${ }^{3}$ \\ and Jong Bang Eun ${ }^{4}$
}

'Department of Food Process Engineering and Postharvest Technology, Institute of Technology, Ambo University, Kebele 01, 1000

Ambo, Ethiopia

${ }^{2} S$ chool of Chemical and Bioengineering, Institute of Technology, Addis Ababa University, King George 04, 1000 Addis Ababa, Ethiopia

Traditional and Modern Medicine Research Directorate, Ethiopian Public Health Institute, Arbegnoch, 1000 Addis Ababa, Ethiopia ${ }^{4}$ Department of Food Science and Technology and BK21 Plus Program, Graduate School of Chonnam National University, 77 Yongbong-ro, Buk-gu, 500-757, 61186 Gwangju, South Korea

Received: 30 May 2018 Accepted: 17 January 2019

\section{(c) (i) ()}

${ }^{*}$ Corresponding author:

Phone: +251911738353

Fax: +251112365639

E-mail: debeworku2010@gmail.com

ORCID IDs: 0000-0001-6027-1388 (Dadi), 0000-0001-7250-1988 (Emire), 0000-

-0003-1666-1578 (Hagos), 0000-0002-2917-4923 (Eun)

\section{SUMMARY}

Moringa stenopetala is a multipurpose plant having high nutritional and medicinal values. The aim of this study is to evaluate the effect of time and temperature of ultrasound-assisted extraction on bioactive compounds and antioxidant activities of $M$. stenopetala leaf extract. The ultrasound-assisted extraction took place at each of 30,40 and 50 ${ }^{\circ} \mathrm{C}$ for 10, 20 and $30 \mathrm{~min}$. The study also included the analysis of the interaction effects of time and temperature on the total phenolic content, total flavonoid content, antioxidant activity (ABTS and DPPH assay), FRAP and chelating activity. The highest total phenolic content, expressed in mg gallic acid equivalents per $\mathrm{g}$ dry mass, was 46.6 and total flavonoid content, expressed in $\mathrm{mg}$ catechin equivalents per g dry mass, was 20.4 at $40^{\circ} \mathrm{C}$ for $20 \mathrm{~min}$. Under the same conditions, the highest antioxidant activities evaluated by DPPH, ABTS and FRAP, expressed in mg Trolox equivalents per $g$ dry mass, were 336.5, 581.8 and 133.3 respectively, and chelating activity, expressed in mg EDTA equivalents per $g$ dry mass, was 28.4. The lowest amounts of bioactive compounds and antioxidant activities were observable when the extraction occurred at $50^{\circ} \mathrm{C}$ for $30 \mathrm{~min}$, followed by the extraction at lower temperature $\left(30^{\circ} \mathrm{C}\right)$ for shorter time $(10 \mathrm{~min})$. The morphological analysis of the residues obtained after extraction using scanning electron microscope indicated that there was a higher ultrasonic destruction of the structural components of the sample at longer extraction time. Therefore, ultrasound-assisted extraction at a temperature of 40 ${ }^{\circ} \mathrm{C}$ for $20 \mathrm{~min}$ is the best time-temperature combination to extract bioactive compounds from M. stenopetala leaves.

Key words: Moringa stenopetala, ultrasound-assisted extraction, bioactive compounds, antioxidant activity

\section{INTRODUCTION}

Moringa stenopetala, often referred to as the African moringa tree, is a multipurpose tree with nutritional and medicinal values, used as oil source or for water clarification (1-3). It is native to Southern Ethiopia, Northern Kenya and Eastern Somalia with the ability to adapt to a wide range of climates from the arid to humid (4). In Ethiopia, there is a widespread cultivation of moringa tree, which could expand the production, thereby increasing the alternative sources of bioactive compounds, and reduce the burden on highly consumed plants. Moringa tree contains a reasonable amount of amino acids, minerals and vitamins that can be used to develop nutritional supplements $(1,5)$.

Moringa species contain a high concentration of phenolic and flavonoid compounds, like cryptochlorogenic acid, isoquercetin and astragalin $(6,7)$, rutin (8), and glucosinolates and isothiocyanates (9). The antioxidant activity of $M$. stenopetala leaf extract is far superior to the antioxidant activity of $M$. oleifera leaf extract (8). Therefore, this plant is a potential source of natural antioxidants $(8,10)$ that serve as anti-inflammatory $(11)$, anti-atherosclerotic $(12,13)$, antihypertensive agents as well as for the prevention and treatment of haematological and hepatorenal disorders (14). Because of these numerous medicinal benefits and nutritional values, this plant can be popularized and promoted for the development of various food and pharmaceutical products. 
Therefore, extracted bioactive compounds from M. stenopetala leaf can be used in the production of natural products serving as food additives and substitute for synthetic antioxidants. As epidemiological studies show, the consumption of synthetic antioxidants possibly poses health risks, like carcinogenic effect (15-17). As stated by Sreelatha and Padma (18), phenolic and flavonoid compounds are considered as safe natural antioxidants.

For efficient utilization of the plant active compounds, it is important to design the best extraction method (6). There are different conventional and novel technologies for the extraction of bioactive compounds from plants. Nowadays, novel extraction technologies like ultrasound-assisted extraction are getting more attention because of their shorter time and lower energy consumption, and higher extraction efficiency (19). These methods are also known to be environmentally friendly since they use smaller volumes of extraction solvents $(19,20)$. Therefore, ultrasound-assisted extraction is relatively safe, non-toxic, it accelerates mass transport and is considered green technology compared to the conventional extraction methods $(19,21)$. During the extraction, the interaction of the high power intensity and sound wave frequency with the material leads to the formation of cavitation $(20,22)$. This is followed by the implosion of the cavitation bubbles in the solvent and on the surfaces of the sample, which cause physical and chemical changes of the sample (19). These changes result in the destruction of the cell wall, which in turn improves the release of the extracts $(20,23)$.

According to some studies, ultrasound-assisted extraction yields significantly higher concentration of phenolic compounds from peaches and pumpkin (24) and flavonoid compounds from Rosmarinus officinalis (25), and higher antioxidant activity of Origanum majorana extract (26) than the conventional extraction method. Therefore, application of ultrasound in the extraction of bioactive compounds from M. stenopetala leaves may be one of the important techniques for their efficient release. However, no research has been done on the effects of ultrasound-assisted extraction on the bioactive compounds of $M$. stenopetala leaf extract. Therefore, the objective of this study is to evaluate the effects of the ultrasonic extraction time and temperature on bioactive compounds from $M$. stenopetala leaves and their antioxidant activity.

\section{MATERIALS AND METHODS}

\section{Sample collection}

The Moringa stenopetala leaves were collected from Arba Minch, located at $6^{\circ} 01^{\prime} 59^{\prime \prime} \mathrm{N}$ and $37^{\circ} 32^{\prime} 59^{\prime \prime} \mathrm{E}$, an altitude of $1269 \mathrm{~m}$ above sea level and $505 \mathrm{~km}$ away from the capital of Ethiopia, Addis Ababa (5). The collected sample was washed immediately using distilled water to remove dirt. Subsequently, the sample was dried for $72 \mathrm{~h}$ in a room with an average temperature of $25^{\circ} \mathrm{C}$ and $62 \%$ relative humidity. The temperature and relative humidity were measured using the iButton temperature/humidity logger (DS1923; Maxim
Integrated Products, Inc., San Jose, CA, USA). The sample was ground using an electric blender (SMX-757; Shinil Industrial Co. Ltd., Seoul, South Korea) and allowed to pass through a sieve (20 meshes). The ground sample was then kept in a sealed polyethylene bag and stored in the dark place at ambient temperature until extraction was done.

\section{Chemicals and reagents}

All chemicals and reagents used were of analytical grade. Ethanol, methanol, iron(III) chloride, aluminium chloride, potassium persulfate, sodium nitrite, iron(II) sulfate, acetic acid, sodium acetate trihydrate, ethyl acetate and hydrochloric acid were from Dae-Jung (Gyeonggi, Korea). Folin-Ciocalteu phenol reagent, 2,2-diphenyl-1-picrylhydrazyl (DPPH), 2,2'-azino-bis(3-ethylbenzothiazoline-6-sulfonic acid) diammonium salt (ABTS), 2,4,6-Tris(2-pyridyl)-s-triazine (TPTZ), sodium hydroxide, ferrozine, 6-hydroxy-2,5,7,8-tetramethylchroman-2-carboxylic acid (Trolox), ethylenediaminetetraacetic acid (EDTA), catechin and gallic acid were from Sigma-Aldrich, Merck (Darmstadt, Germany).

\section{Maceration}

The conventional extraction by maceration was performed according to the method explained by Vongsak et al. (10) with some modifications. The leaf powder (5 g) was put in $200 \mathrm{~mL}$ of $70 \%$ ethanol with a sample-to-solvent ratio of 1:40 ( $\mathrm{g} / \mathrm{mL})$. Subsequently, it was placed in the shaking water bath (JSSB-50T; JS Research Inc., Gongju, South Korea) at $100 \mathrm{rpm}$ and $30^{\circ} \mathrm{C}$ for $24 \mathrm{~h}$. The extract was filtered through Whatman no. 1 filter paper and dried using a rotary evaporator (WB 2001; Heidolph, Schwabach, Germany) under vacuum at $40^{\circ} \mathrm{C}$. The dried extract was kept in a refrigerator at 4 ${ }^{\circ} \mathrm{C}$ until it was required for the analysis.

\section{Ultrasound-assisted extraction}

The extraction of $M$. stenopetala leaves was done using ultrasonic bath (SONOREX ${ }^{\mathrm{TM}}$ SUPER RK $510 \mathrm{H}$; Bandelin electronic $\mathrm{GmbH} \&$ Co. KG; Berlin, Germany) designed with a fixed frequency of $35 \mathrm{kHz}$ and power intensity $160 \mathrm{~W}$. The sample $(5 \mathrm{~g})$ was mixed with $200 \mathrm{~mL}$ of $70 \%$ ethanol in the flask in the ratio of 1:40 $(\mathrm{g} / \mathrm{mL})$. The ultrasound-assisted extraction was done at different temperatures $\left(30,40\right.$ and $\left.50{ }^{\circ} \mathrm{C}\right)$ and time (10, 20 and $30 \mathrm{~min}$ ) for each temperature. The extracts were then filtered through Whatman no. 1, dried using a rotary evaporator (WB 2001; Heidolph) under vacuum at $40^{\circ} \mathrm{C}$, and stored at $4{ }^{\circ} \mathrm{C}$ until they were required for the analysis.

\section{Extraction of bound phenolic compounds}

The extraction of the bound phenols was done according to the method described by Uribe et al. (27) with some modifications. About one gram of the residue obtained after extraction was taken and $5 \mathrm{~mL}$ of $3 \mathrm{M} \mathrm{NaOH}$ were added. The mixture was kept in the shaking water bath (JSSB-50T; JS 
Research Inc.) at $30^{\circ} \mathrm{C}$ for $9 \mathrm{~h}$ and kept at room temperature $\left(25^{\circ} \mathrm{C}\right)$ for $12 \mathrm{~h}$ for complete digestion. Then, $5 \mathrm{~mL}$ of $3 \mathrm{M} \mathrm{HCl}$ were added to acidify the mixture to $\mathrm{pH}=2$, which was then kept for additional $4 \mathrm{~h}$ at room temperature. The mixture was then centrifuged (Union 32R plus; Hanil Science Industrial Co., Ltd., Seoul, South Korea) at $1915 \times g$ for $15 \mathrm{~min}$. The supernatant was taken and mixed with $10 \mathrm{~mL}$ of ethyl acetate (three times) and the upper clear solution was collected. The collected ethyl acetate fraction was dried using rotary evaporator (WB 2001; Heidolph) under vacuum at $37^{\circ} \mathrm{C}$. Then, the dried extract was dissolved in $10 \mathrm{~mL}$ of $70 \%$ ethanol to measure the bound phenolic and flavonoid compounds with the same procedure for free phenolic and flavonoid content measurements described below.

\section{Determination of total phenolic content}

The total phenolic content (TPC) was determined according to Dadi et al. (28). The extracts $(0.5 \mathrm{~mL})$ were mixed with $2.5 \mathrm{~mL}$ of the $10 \%$ aqueous (V/V) Folin-Ciocalteu reagent. After $8 \mathrm{~min}, 2.0 \mathrm{~mL}$ of $7.5 \%(\mathrm{~m} / \mathrm{V})$ sodium carbonate were added, mixed and kept in the dark at room temperature for $2 \mathrm{~h}$. The same procedure was used for the blank and gallic acid standard prepared at different concentrations $(0,50,100,150$, 200,250 and $300 \mu \mathrm{g} / \mathrm{mL}$ ) to get a standard curve. The absorbance was measured at $765 \mathrm{~nm}$ using a UV-Vis spectrophotometer (Optizen 2120UV; Mecasys Co. Ltd., Daejeon, South Korea). The TPC was expressed in mg gallic acid equivalents (GAE) per gram of dry mass of the sample.

\section{Determination of total flavonoid content}

The total flavonoid content (TFC) was determined according to Adom and Liu (29) with a slight modification. The extract $(0.5 \mathrm{~mL})$ was mixed with $0.15 \mathrm{~mL}$ of $5 \%(\mathrm{~m} / \mathrm{V})$ sodium nitrite and $2.5 \mathrm{~mL}$ of distilled water and kept for $6 \mathrm{~min}$. A volume of 0.3 $\mathrm{mL}$ aluminium chloride $(10 \% \mathrm{~m} / \mathrm{V})$ was then added and mixed. This was followed by the addition of $1 \mathrm{~mL}$ of $1.0 \mathrm{M}$ sodium hydroxide and then $0.55 \mathrm{~mL}$ of distilled water. The mixture was vortexed and kept for $15 \mathrm{~min}$. Finally, the concentration was measured at $510 \mathrm{~nm}$ using UV-Vis spectrophotometer (Optizen 2120UV; Mecasys Co. Ltd). The same procedure, only without the extract, was applied for the blank and catechin standard at different concentrations $(0,50,100,150,200,250$ and $300 \mu \mathrm{g} /$ $\mathrm{mL}$ ) to get the standard curve. The TFC was expressed in $\mathrm{mg}$ catechin equivalents (CE) per gram of dry sample.

\section{DPPH radical scavenging activity}

The free radical scavenging activity was measured using the 2,2-diphenyl-1-picrylhydrazyl (DPPH) as described by Brand-Williams et al. (30). The DPPH solution (2.4 mg) in 100 $\mathrm{mL}$ of $80 \%$ ethanol was prepared and the absorbance was checked for the reading of less than one at $515 \mathrm{~nm}$ to ensure the optimum reagent concentration for determination of the scavenging activity. A volume of $0.1 \mathrm{~mL}$ of the sample or Trolox standard of different concentrations was mixed with $3.9 \mathrm{~mL}$ of DPPH solution. The mixtures were then mixed and kept in the dark at room temperature for $30 \mathrm{~min}$. Subsequently, the absorbance was measured at $515 \mathrm{~nm}$ using UV-Vis spectrophotometer (Optizen 2120UV; Mecasys Co. Ltd). The antioxidant activity was calculated from the Trolox standard curve and expressed in mg Trolox equivalents (TE) per gram of dry mass.

\section{$A B T S^{+}$radical scavenging assay}

The $\mathrm{ABTS}^{+}$radical scavenging activity was assayed according to the method described by Re et al. (31). The ABTS radical cation $\left(\mathrm{ABTS}^{+}\right.$) was produced by reacting $7 \mathrm{mM}$ ABTS solution with $2.45 \mathrm{mM}$ potassium persulfate and incubated for 12 to $16 \mathrm{~h}$ in the dark at room temperature. This solution was then diluted using ethanol to obtain an absorbance of $0.70 \pm 0.02$ at $734 \mathrm{~nm}$ using a UV-Vis spectrophotometer (Optizen 2120UV; Mecasys Co. Ltd). After optimizing the ABTS reagent, $50 \mu \mathrm{L}$ of the sample extracts and the standard in different concentrations dissolved in $80 \%$ ethanol were added to $5 \mathrm{~mL}$ of the $\mathrm{ABTS}^{+}$solution and mixed thoroughly. The Trolox standard at different concentrations and blank solution were prepared using $80 \%$ ethanol instead of the sample solution and assayed under the same conditions. Finally, the antioxidant activity was calculated from the Trolox standard curve and expressed in mg TE per gram of dry mass.

\section{Ferric reducing antioxidant power}

The ferric reducing antioxidant power (FRAP) assay was done according to Nguyen et al. (32). First, $300 \mathrm{mM}$ acetate buffer solution ( $\mathrm{pH}=3.6)$ was prepared from acetic acid and sodium acetate trihydrate according to Benzie and Strain (33). The FRAP solution was then prepared by mixing the acetate buffer solution, $10 \mathrm{mM}$ tripyridyltriazine (TPTZ) solution in 40 $\mathrm{mM}$ hydrochloric acid and $20 \mathrm{mM} \mathrm{FeCl}_{3} \cdot 6 \mathrm{H}_{2} \mathrm{O}$ solution in the ratio of 10:1:1, respectively. Then, $0.15 \mathrm{~mL}$ of the extracts or standard (Trolox) solutions were mixed with $2.85 \mathrm{~mL}$ of fresh FRAP solution. The mixture was then kept for $30 \mathrm{~min}$ in the dark at ambient temperature including the blank. Then, the absorbance was measured at $593 \mathrm{~nm}$ using a UV-Vis spectrophotometer (Optizen 2120UV; Mecasys Co. Ltd). The reducing power was calculated from the Trolox standard curve and expressed in mg TE per gram of dry mass.

\section{Ferrous ion chelating activity assay}

The chelating activity of the extract was done based on the procedure described by Chew et al. (34). Briefly, $1 \mathrm{~mL}$ of $0.1 \mathrm{mM}$ iron(II) sulfate was added to $1 \mathrm{~mL}$ of the extract, followed by the addition of $1 \mathrm{~mL}$ of $0.25 \mathrm{mM}$ ferrozine solution. The mixture was shaken vigorously and allowed to stand for $10 \mathrm{~min}$ at room temperature in the dark. The same procedure was done for EDTA standard at different concentrations and the blank. Then, the absorbance was measured using UV-Vis spectrophotometer (Optizen 2120UV; Mecasys Co. Ltd) at $562 \mathrm{~nm}$. 
The iron(II)-chelating activity of the extract was calculated and expressed in mg EDTA equivalents (EE) per gram of dry mass using the EDTA standard curve.

\section{Scanning electron microscopy}

After the completion of extraction, the residues were allowed to dry in the oven (FO-600M; Jeio Tech, Seoul, South Korea) at $40{ }^{\circ} \mathrm{C}$ for $4 \mathrm{~h}$. Then, the sample was put on a plate with double-sided adhesive tape and vacuum coated with platinum. The morphological analysis was done using scanning electron microscope (JSM-7500F; JEOL Ltd., Tokyo, Japan) at an accelerated voltage of $15 \mathrm{kV}$ and with a magnification of $500 \times$.

\section{Statistical analysis}

All experiments were conducted in triplicate and results were reported as mean value \pm standard deviation. The statistical analyses were done using analysis of variance (ANOVA), Duncan's post-hoc test with a significant level of $p \leq 0.05$. The Pearson's correlation coefficient test was used to determine the correlation between the antioxidant activity, and TPC and TFC. All the data were analyzed by IBM SPSS, v. 20.0 (35).

\section{RESULTS AND DISCUSSION}

\section{Effects of time and temperature of ultrasound-assisted extraction on TPC and TFC}

When the ultrasound-assisted extraction and conventional (maceration) extraction techniques were compared, generally, the yield of TPC and TFC after ultrasound-assisted extraction was significantly $(\mathrm{p} \leq 0.05)$ higher than of the macerated extract (Table 1). However, the maceration extraction gave higher TPC and TFC than the ultrasound-assisted extraction at $30^{\circ} \mathrm{C}$ for $10 \mathrm{~min}$ and $50^{\circ} \mathrm{C}$ for $30 \mathrm{~min}$ (Table 1), which might be due to the insufficient extraction time or to the possible destruction of the extracted TPC and TFC because of longer exposure to the ultrasound at higher temperature, respectively. Even if conventional extraction technique has comparable yield of TPC and TFC to some time and temperature combinations of ultrasound-assisted extraction, the time of the extraction was too short compared to maceration extraction that took $24 \mathrm{~h}$. As stated by Chemat et al. (20), conventional extraction methods are characterized by requirement for lengthy time, high energy and a higher volume of harmful chemicals. The results of the current work are in agreement with the findings of Das and Eun (36), who reported similar extraction efficiency of agitation and ultrasound-assisted extraction. On the contrary, Ahmed et al. (37) reported that the TPC and TFC were significantly higher in the cold-brewed coffee extract obtained by ultrasound-assisted extraction.

The TPC and TFC of M. stenopetala leaf extracts increased with the increase in the temperature of ultrasound-assisted extraction (Table 1). On the other hand, the TPC and TFC decreased when the extraction temperature was $50{ }^{\circ} \mathrm{C}$, although they were significantly higher than in the extract obtained after $10 \mathrm{~min}$ at $30^{\circ} \mathrm{C}$. Extraction temperature improves the yield of bioactive compounds. The increase in temperature improves the solubility of active compounds by facilitating the penetration of the solvent (19), due to the decrease of viscosity and surface tension of the solvent (26).

Table 1. The total phenolic (TPC) and flavonoid contents (TFC) on dry mass basis of Moringa stenopetala leaves extracted by ultrasonication at different temperatures and time, and by maceration

\begin{tabular}{cccc}
$\begin{array}{c}\text { Extraction } \\
\text { temperature/ }{ }^{\circ} \mathrm{C}\end{array}$ & $\begin{array}{c}t \text { (extraction)/ } \\
\text { min }\end{array}$ & $\begin{array}{c}W(\mathrm{TPC} \text { as } \\
\mathrm{GAE}) /(\mathrm{mg} / \mathrm{g})\end{array}$ & $\begin{array}{c}w(\mathrm{TFC} \text { as } \\
\mathrm{CE}) /(\mathrm{mg} / \mathrm{g})\end{array}$ \\
\multirow{3}{*}{30} & 10 & $(33.4 \pm 1.2)^{\mathrm{f}}$ & $(13.0 \pm 0.4)^{\mathrm{e}}$ \\
& 20 & $(44.5 \pm 0.6)^{\mathrm{b}}$ & $(16.1 \pm 0.5)^{\mathrm{cd}}$ \\
& 30 & $(44.5 \pm 0.5)^{\mathrm{b}}$ & $(17.0 \pm 0.4)^{\mathrm{bc}}$ \\
40 & 10 & $(45.5 \pm 0.5)^{\mathrm{b}}$ & $(19.5 \pm 0.6)^{\mathrm{a}}$ \\
& 20 & $(46.6 \pm 0.3)^{\mathrm{a}}$ & $(20.4 \pm 0.5)^{\mathrm{a}}$ \\
& 30 & $(42.0 \pm 0.4)^{\mathrm{d}}$ & $(15.3 \pm 0.5)^{\mathrm{d}}$ \\
50 & 10 & $(43.3 \pm 0.5)^{\mathrm{c}}$ & $(15.6 \pm 0.4)^{\mathrm{d}}$ \\
& 20 & $(42.9 \pm 0.5)^{\mathrm{cd}}$ & $(11.6 \pm 0.7)^{\mathrm{f}}$ \\
Maceration & 30 & $(39.8 \pm 0.3)^{\mathrm{e}}$ & $(8.8 \pm 0.8)^{\mathrm{g}}$ \\
& & $(43.0 \pm 0.5)^{\mathrm{cd}}$ & $(17.2 \pm 0.8)^{\mathrm{b}}$ \\
\hline
\end{tabular}

All values were expressed as mean \pm standard deviation $(N=3)$. Values with different superscript letters in each column indicate significant difference $(p<0.05)$. GAE=gallic acid equivalents, $C E=$ catechin equivalents

As shown in Table 1, the ultrasound-assisted extraction at $40{ }^{\circ} \mathrm{C}$ for $20 \mathrm{~min}$ gave the highest TPC as GAE $(46.6 \mathrm{mg} / \mathrm{g} \mathrm{dm})$ and TFC as CE $(20.4 \mathrm{mg} / \mathrm{g} \mathrm{dm})$, followed by extraction at $30^{\circ} \mathrm{C}$ for $30 \mathrm{~min}$. On the contrary, the lowest yields of TPC and TFC were obtained at $30{ }^{\circ} \mathrm{C}$ for $10 \mathrm{~min}$ and $50{ }^{\circ} \mathrm{C}$ for $30 \mathrm{~min}$. This indicates that during ultrasound-assisted extraction, the use of lower temperature and shorter extraction time may result in an insufficient extraction of bioactive compounds, whereas the longer extraction time at a higher temperature may cause an ultrasonic destruction of bioactive compounds. This could be due to the sensitivity of the bioactive compounds to heat and longer exposure to the ultrasonication. Santos et al. (38) reported that the increase of temperature during ultrasound-assisted extraction leads to the increase of the vapour pressure of the solvents, which results in lower cavitation force, leading to the decreased yield of bioactive compounds. Besides, it was reported that lower temperature is preferred for extraction of bioactive compounds (19). This phenomenon was also reported for the ultrasound-assisted extraction of rosmarinic acid when the temperature was increased from 30 to $60^{\circ} \mathrm{C}$ (39).

According to this study, the best combination of time and temperature for the ultrasound-assisted extraction of TPC and TFC from M. stenopetala leaves is $40^{\circ} \mathrm{C}$ for $20 \mathrm{~min}$. Similarly, the highest TPC was obtained from Origanum majorana leaves at $35^{\circ} \mathrm{C}$ for $10 \mathrm{~min}$ (26), from Rosmarinus officinalis leaves at $50^{\circ} \mathrm{C}$ for $10 \mathrm{~min}$ (39), from Achillea biebersteinii at 35 ${ }^{\circ} \mathrm{C}$ for $35 \mathrm{~min}(40)$ and from citrus peel extract at $15^{\circ} \mathrm{C}$, while at $40^{\circ} \mathrm{C}$ lower values were obtained (41). These differences might be due to the variation of the ultrasonic parameters and the structure of the plant constituents. 
The yield of bioactive compounds of $M$. stenopetala leaf extract was significantly different when different ultrasonicators with different power and frequency were used, which is in agreement with Chemat et al. (19). When the ultrasonicator power and frequency were increased from 160 to $190 \mathrm{~W}$ and 35 to $48 \mathrm{kHz}$ respectively, the TPC and TFC increased (data not shown). As described by Santos et al. (38), not all ultrasonicators perform equally. Increase in the ultrasonic power damages the cell wall, subsequently leading to better release of the bioactive compounds to the solvent (26). During ultrasound-assisted extraction of $M$. stenopetala leaves, there was no significant difference in the yield of TPC and TFC with the prolongation of extraction time from 20 to $30 \mathrm{~min}$ at $30^{\circ} \mathrm{C}$ and from 10 to $20 \mathrm{~min}$ at $40^{\circ} \mathrm{C}$, respectively (Table 1 ).

\section{Effect of time and temperature of ultrasound-assisted extraction on the antioxidant activity}

The ultrasound-assisted extraction of $M$. stenopetala leaves gave higher antioxidant activity than the conventional (maceration) extraction technique (Table 2). This shows that ultrasound-assisted extraction is more efficient in extracting antioxidant compounds than the conventional method. Similar trend was reported for the ultrasound-assisted extraction of cold-brewed coffee (37) and Origanum majorana leaves (26).

The antioxidant activity of $M$. stenopetala leaf extract was significantly affected by ultrasound-assisted extraction time and temperature (Table 2). The higher the temperature, the lower the antioxidant activity. This might be due to the destruction of bioactive compounds at higher temperatures. The highest antioxidant activity was achieved at $40^{\circ} \mathrm{C}$ for 20 min, at which the highest yields of TPC and TFC were obtained. This was also confirmed with a significant positive correlation $(p<0.01)$ between the antioxidant activities and the TPC and TFC of the extract $(r=0.51-0.88)$. The highest values of the DPPH as TE $(336.5 \mathrm{mg} / \mathrm{g})$ and ABTS as TE $(581.8 \mathrm{mg} / \mathrm{g})$ were found in the extract obtained at $40^{\circ} \mathrm{C}$ for $20 \mathrm{~min}$. When the values of DPPH and ABTS are compared, the range of DPPH values is relatively higher than of ABTS values as ultrasound-assisted extraction time and temperature are changed
(Table 2). Moreover, ABTS values were higher than the DPPH values (Table 2). The same trend was also reported by Ahmed et al. (37) for cold-brewed coffee extracts, which might be due to the stronger tendency of ABTS radicals to donate electron than of the DPPH radical.

The FRAP value was significantly higher when the time and temperature of ultrasound-assisted extraction of $40{ }^{\circ} \mathrm{C}$ for $10 \mathrm{~min}$ were used, followed by $20 \mathrm{~min}$ extraction at the same temperature, and for $10 \mathrm{~min}$ at $50^{\circ} \mathrm{C}$. This indicates that the FRAP value is higher when the extraction time is shorter. This finding is also in agreement with Hossain et al. (26). On the other hand, the lowest reducing power of $M$. stenopetala leaf extract was found when the temperature of ultrasound-assisted extraction was $50{ }^{\circ} \mathrm{C}$ for $30 \mathrm{~min}$. This might be due to the degradation of bioactive compounds at higher temperature. The effects of the time and temperature of ultrasound-assisted extraction are different for different compounds (19). This is due to the variation of the structural composition of the plant cell that can have effects on the ultrasonic extraction efficiency. Therefore, it is important to find optimum time and temperature of ultrasound-assisted extraction that can improve the extraction efficiency and antioxidant activity.

\section{Bound TPC and TFC}

Bound phenolic and flavonoid compounds have comparable biological activities with soluble phenolic compounds in terms of anticancer, anti-inflammatory and other positive health effects $(42,43)$. Bound phenolic compounds are covalently bound to the cell wall matrix, thus the alkaline and acid hydrolysis followed by ethyl acetate extraction methods are commonly used to free them from the cell wall matrix and measure the yield (42). The effects of ultrasound-assisted extraction time on free and bound phenolic and flavonoid content were examined and compared with the maceration extraction technique. There were significant differences in bound phenolic and flavonoid compounds (Fig. 1a and Fig. $1 \mathrm{~b}$ ) as the ultrasound-assisted extraction time was increased from $10 \mathrm{~min}$ to $30 \mathrm{~min}$.

Table 2. Antioxidant activity on dry mass basis of Moringa stenopetala leaf extracted by ultrasonication at different temperatures and time, and by maceration

\begin{tabular}{cccccc}
$\begin{array}{c}\text { Extraction tempera- } \\
\text { ture }{ }^{\circ} \mathrm{C}\end{array}$ & $\begin{array}{c}t \text { (extraction)/ } \\
\text { min }\end{array}$ & $\begin{array}{c}w(\mathrm{DPPH} \text { as } \\
\mathrm{TE}) /(\mathrm{mg} / \mathrm{g})\end{array}$ & $\begin{array}{c}w(\mathrm{ABTS} \text { as } \\
\mathrm{TE}) /(\mathrm{mg} / \mathrm{g})\end{array}$ & $\begin{array}{c}w(\mathrm{FRAP} \text { as } \\
\mathrm{TE}) /(\mathrm{mg} / \mathrm{g})\end{array}$ & $\begin{array}{c}w(\text { chelation as } \\
\mathrm{EE}) /(\mathrm{mg} / \mathrm{g})\end{array}$ \\
\multirow{3}{*}{30} & 10 & $(230.7 \pm 2.2)^{\mathrm{f}}$ & $(444.4 \pm 3.9)^{\mathrm{f}}$ & $(121.2 \pm 0.6)^{\mathrm{e}}$ & $(24.2 \pm 0.3)^{\mathrm{e}}$ \\
& 20 & $(232.2 \pm 1.4)^{\mathrm{f}}$ & $(498.9 \pm 3.9)^{\mathrm{e}}$ & $(130.9 \pm 0.5)^{\mathrm{c}}$ & $(24.5 \pm 0.2)^{\mathrm{e}}$ \\
& 30 & $(257.3 \pm 1.8)^{\mathrm{d}}$ & $(571.4 \pm 4.5)^{\mathrm{ab}}$ & $(133.1 \pm 0.6)^{\mathrm{b}}$ & $(25.6 \pm 0.4)^{\mathrm{c}}$ \\
\multirow{2}{*}{40} & 10 & $(273.6 \pm 0.9)^{\mathrm{b}}$ & $(572.7 \pm 3.9)^{\mathrm{ab}}$ & $(141.0 \pm 0.5)^{\mathrm{a}}$ & $(26.9 \pm 0.3)^{\mathrm{b}}$ \\
& 20 & $(336.5 \pm 1.8)^{\mathrm{a}}$ & $(581.8 \pm 8.1)^{\mathrm{a}}$ & $(133.3 \pm 0.4)^{\mathrm{b}}$ & $(28.4 \pm 0.3)^{\mathrm{a}}$ \\
& 30 & $(260.3 \pm 1.8)^{\mathrm{d}}$ & $(567.5 \pm 5.9)^{\mathrm{bc}}$ & $(104.9 \pm 0.6)^{\mathrm{f}}$ & $(26.4 \pm 0.3)^{\mathrm{b}}$ \\
50 & 10 & $(265.0 \pm 1.4)^{\mathrm{c}}$ & $(571.4 \pm 9.8)^{\mathrm{ab}}$ & $(133.2 \pm 0.8)^{\mathrm{b}}$ & $(24.7 \pm 0.2)^{\mathrm{de}}$ \\
& 20 & $(220.7 \pm 1.4)^{\mathrm{g}}$ & $(549.4 \pm 3.9)^{\mathrm{d}}$ & $(128.6 \pm 0.6)^{\mathrm{d}}$ & $(23.3 \pm 0.2)^{\mathrm{f}}$ \\
Maceration & 30 & $(166.3 \pm 1.8)^{\mathrm{h}}$ & $(435.3 \pm 8.1)^{\mathrm{f}}$ & $(98.3 \pm 0.5)^{\mathrm{g}}$ & $(22.9 \pm 0.3)^{\mathrm{f}}$ \\
& & $(242.6 \pm 0.9)^{\mathrm{e}}$ & $(558.6 \pm 2.2)^{\mathrm{cd}}$ & $(128.8 \pm 0.4)^{\mathrm{d}}$ & $(25.1 \pm 0.6)^{\mathrm{d}}$ \\
\hline
\end{tabular}

All values were expressed as mean \pm standard deviation $(N=3)$. Values with different superscript letters in each column indicate significant difference $(p<0.05)$. TE=Trolox equivalents, EE=EDTA equivalents 
a)

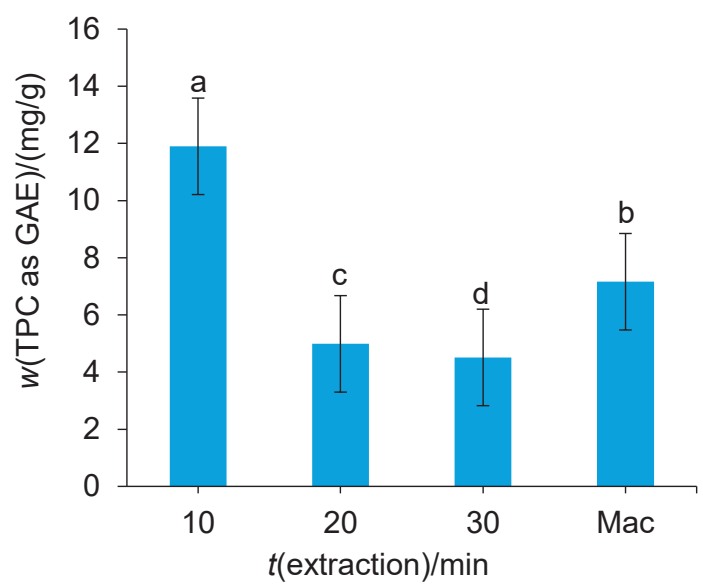

b)

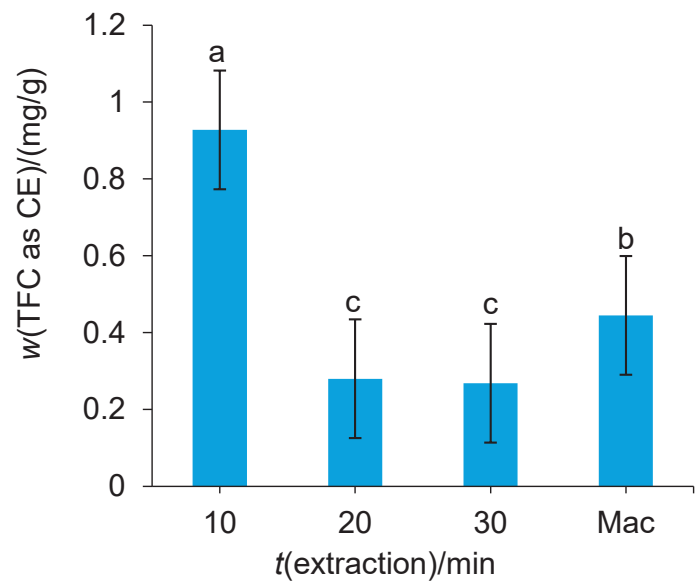

Fig. 1. Mass fractions of: a) bound total phenolic (TPC) and b) flavonoid contents (TFC) on dry mass basis of Moringa stenopetala leaf expressed as gallic acid (GAE) and catechin (CE) equivalents, respectively, at different extraction time, or by maceration. Mac=maceration. Different letters show significant differences $(p<0.05)$

The mass fractions of bound phenolic and flavonoid compounds decreased in the residue when the time of ultrasound-assisted extraction was longer (Fig. 1a and Fig. 1 b). This might be due to the exposure of the sample to the effect of ultrasonication for longer time, which results in the destruction of cellular structure and the release of the bound phenolic and flavonoid compounds to the solvent (43). As a result, there were fewer bound bioactive compounds in the residues. As stated by Chemat et al. (19), ultrasound-assisted extraction disrupts the cell structure and facilitates the penetration of the solvent into the cell components, which increases the mass transfer. As shown in Fig. 1a and Fig. 1b, the highest mass fractions of bound phenolic and flavonoid compounds, respectively, were obtained in the residue after the ultrasound-assisted extraction for $10 \mathrm{~min}$, followed by maceration. This indicates that ultrasound-assisted extraction for $10 \mathrm{~min}$ and maceration are not efficient for the destruction of the cell wall matrix of the plant. Consequently, the fewer bound phenolic and flavonoid compounds are released during free phenolic compound extraction. This was also shown by the higher yield of bound phenolic and flavonoid compounds found in the residues after extraction.

\section{The antioxidant activity of bound phenolic compounds}

As shown in Fig. 2a and Fig. 2b, there are significant differences in the antioxidant activity of the bound phenolic compounds obtained under different conditions of ultrasound-assisted extraction or by maceration. The highest antioxidant activity was found in the residue after ultrasound-assisted extraction for $10 \mathrm{~min}$, followed by the conventionally extracted residue. Moreover, this study indicates that bound phenolic and flavonoid compounds are responsible for the radical scavenging activity. As a result, the higher the mass fraction of bound phenolic and flavonoid compounds, the higher the antioxidant activity (Fig. 1 and Fig. 2). The lowest antioxidant activity was obtained in the residues after ultrasound-assisted extraction for 20 and $30 \mathrm{~min}$. This might be due to the release of the amounts of bound

a)

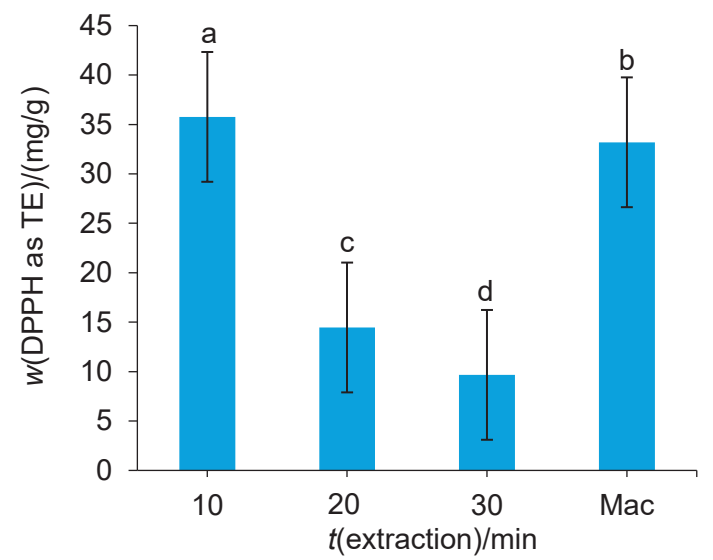

b)

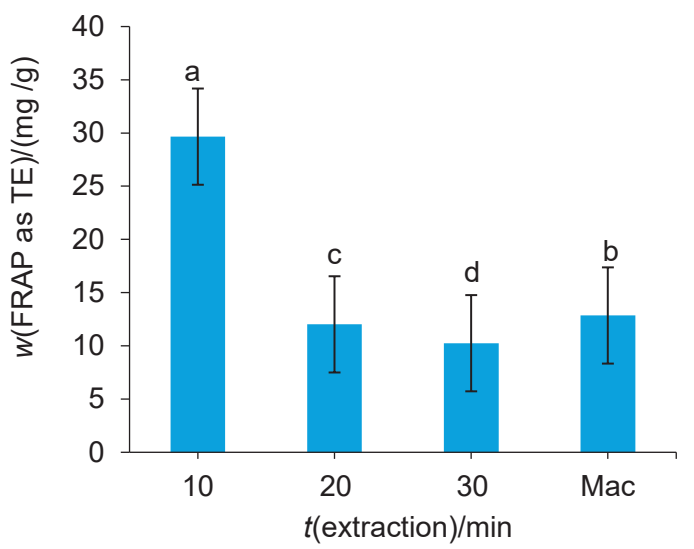

Fig. 2. The antioxidant activity expressed on dry mass basis of bound phenolic compounds extracted from Moringa stenopetala leaves by ultrasound-assisted extraction at different extraction time or by maceration determined using: a) DPPH and b) FRAP assay. $\mathrm{Mac}=$ maceration, $\mathrm{TE}=$ Trolox equivalents. The different letters show significant differences $(p<0.05)$ 
phenolic compounds comparable to the soluble phenolic compounds extracted during ultrasonication. The ultrasonic disruption of the cell wall leads to the release of more bound polyphenols $(37,43)$. As a result, the residues obtained after ultrasound-assisted extraction had lower yield of bound phenolic compounds when the extraction was done for longer time. Therefore, ultrasound-assisted extraction can also be

a)

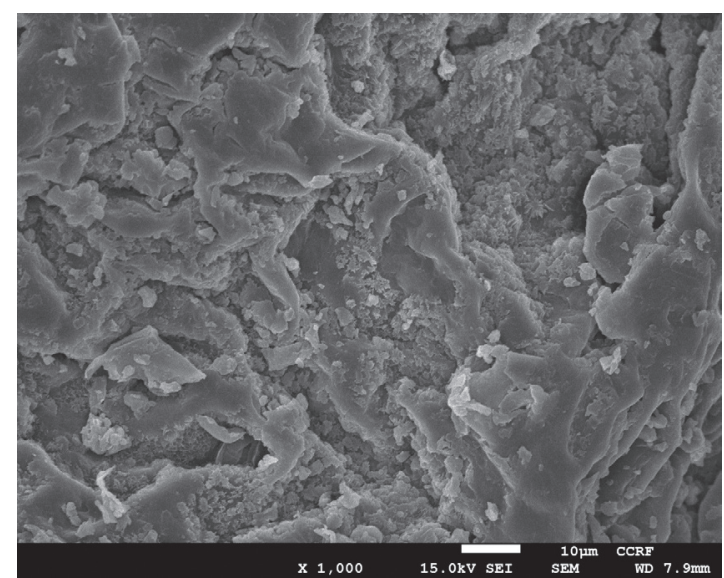

b)

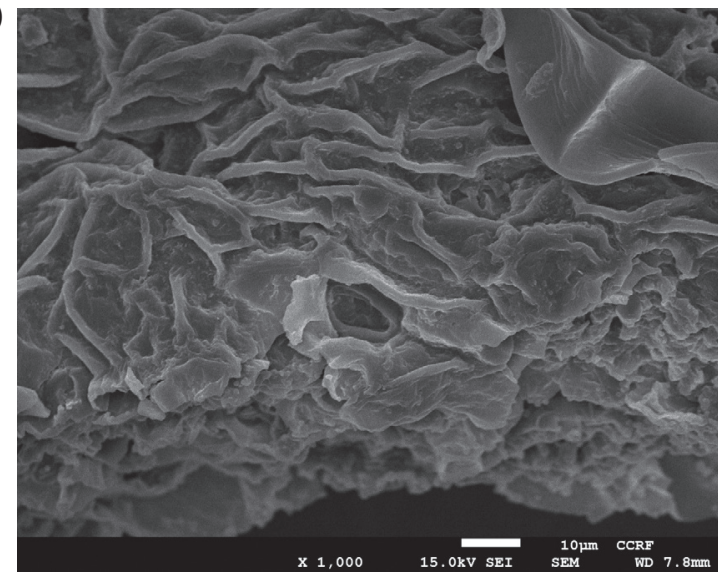

c)

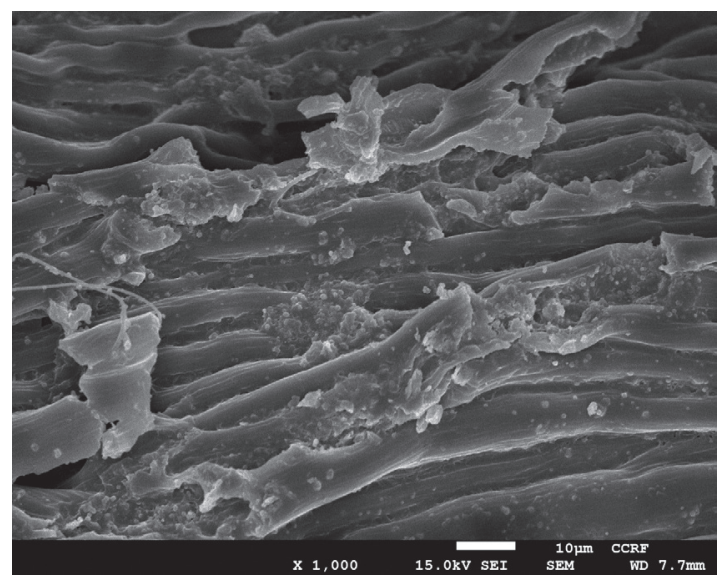

used for the extraction of bound phenolic and flavonoid compounds from $M$. stenopetala leaves, consequently maximizing the antioxidant activity of the extract.

\section{Morphological analysis of the samples as affected by the time of ultrasound-assisted extraction}

The morphological analysis of the samples showed clear differences from the sample before extraction, which had intact structure (Fig. 3a). The intact structure was disrupted and swollen during conventional (maceration) extraction (Fig. 3b). The degree of disruption of the structural constituents of the sample significantly changed during ultrasound-assisted extraction, especially with the prolongation of the time of extraction (Figs. 3c-3e). This is due to the effects of the ultrasonic wave and vibration (19). The increase of the destruction of the cellular structure of the sample increases the diffusion rate and dissolves the active compounds in the solvent, subsequently improving the yield of bioactive compounds.

As shown in the images (Fig. 3), the effect of ultrasonication on the morphological change of the sample was high at shorter time when compared to maceration. This showed the effectiveness of the ultrasonication for the extraction of bioactive

d)

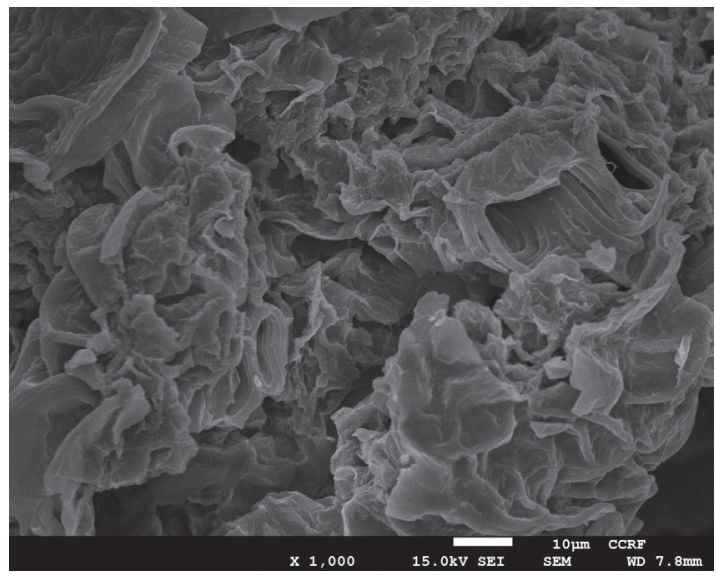

e)

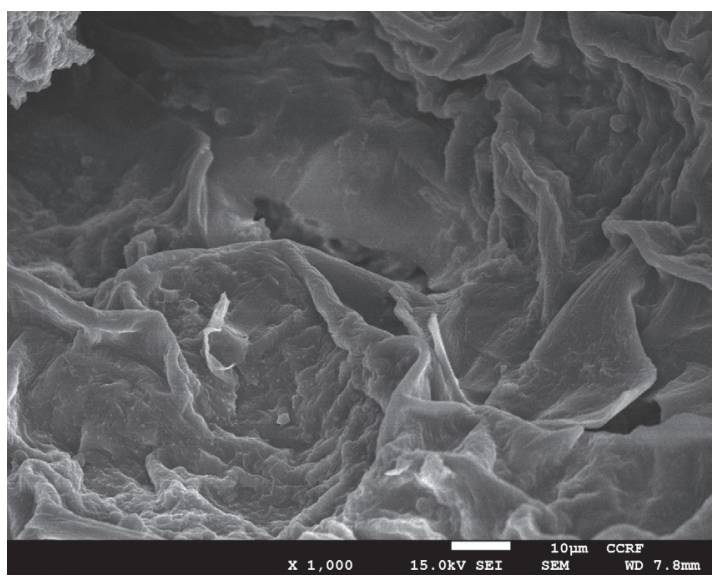

Fig. 3. The morphological images of: a) the sample before extraction, b) the residue after maceration, and after: c) 10 , d) 20 and e) 30 min of ultrasound-assisted extraction 
compounds from the leaves of $M$. stenopetala. According to Altemimi et al. (24) and Chemat et al. (19), conventional extraction did not show significant structural changes compared to the ultrasound-assisted one. The destruction of the structural constituents shown in the residue was relatively higher when the ultrasound-assisted extraction lasted for 30 min (Fig. 3e). As stated by Ma et al. (41), the effect of the ultrasonicator is increased with longer exposure time, which may lead to the release of bioactive compounds by increasing the diffusivity of the solvent. On the other hand, severe destruction of the structure may also have significant effects on the release of active compounds due to the exposure to the ultrasonication wave for a long time. As a result, the bioactive compounds may also be destructed or changed chemically into non-extractable forms.

\section{CONCLUSIONS}

Ultrasound-assisted extraction of Moringa stenopelata leaves is an efficient technique that improves the yield of bioactive compounds and antioxidant activity of the extract. The ultrasound-assisted extraction gave higher yield of bioactive compounds within a short time of extraction and required lower energy consumption than maceration. Therefore, it is favourable process for food and pharmaceutical industries. According to this study, the best time and temperature combination is $20 \mathrm{~min}$ at $40{ }^{\circ} \mathrm{C}$ to get the highest total phenolic and total flavonoid contents with high antioxidant activity. This time and temperature combination was also efficient for extracting the bound phenolic and flavonoid compounds, thus increasing the yield of the bioactive compounds. Further research is required to study the effects of ultrasonic power and frequency on bioactive compounds and antioxidant activity of Moringa stenopetala leaf extracts.

\section{CONFLICT OF INTEREST}

The authors declare no conflict of interest.

\section{ACKNOWLEDGEMENT}

Authors would like to thank for the financial support of Addis Ababa University and National Institute for International Education and Chonnam National University, Gwangju, South Korea.

\section{REFERENCES}

1. Melesse A. Comparative assessment on chemical compositions and feeding values of leaves of Moringa stenopetala and Moringa oleifera using in vitro gas production method. Ethiop J Appl Sci Technol. 2011;2(2):31-41.

2. Jiru D, Sonder K, Alemayehu L, Mekonen Y, Anjulo A. Leaf yield and nutritive value of Moringa stenopetala and Moringa oleifera accessions: Its potential role in food security in constrained dry farming agroforestry system. Proceedings of the Moringa and other highly nutritious plant resources:
Strategies, standards and markets for a better impact on Nutrition in Africa; 2006 November 16-18; Accra, Ghana: Moringa news; 2006. pp. 16-8.

3. Melesse A, Tiruneh W, Negesse T. Effects of feeding Moringa stenopetala leaf meal on nutrient intake and growth performance of Rhode Island Red chicks under tropical climate. Trop Subtrop Agroecosyst. 2011;14(2):485-92.

4. Jahn SAA. The traditional domestication of a multipurpose tree Moringa stenopetala (Bak. f.) Cuf. in the Ethiopian Rift Valley. Ambio. 1991:20(6):244-7.

5. Mikore D, Mulugeta E. Determination of proximate and mineral compositions of Moringa oleifera and Moringa stenopetala leaves cultivated in Arbaminch Zuria and Konso, Ethiopia. Afr J Biotechnol. 2017;16(15):808-18. https://doi.org/10.5897/AJB2017.15919

6. Rodríguez-Pérez C, Quirantes-Piné R, Fernández-Gutiérrez A, Segura-Carretero A. Optimization of extraction method to obtain a phenolic compounds-rich extract from Moringa oleifera Lam leaves. Ind Crops Prod. 2015;66:246-54. https://doi.org/10.1016/j.indcrop.2015.01.002

7. Vongsak B, Sithisarn P, Gritsanapan W. HPLC quantitative analysis of three major antioxidative components of Moringa oleifera leaf extracts. Planta Medica. 2012;78(11):PJ15. https://doi.org/10.1055/s-0032-1321175

8. Habtemariam S, Varghese GK. Extractability of rutin in herbal tea preparations of Moringa stenopetala leaves. Beverages. 2015;1(3):169-82.

https://doi.org/10.3390/beverages1030169

9. Bennett RN, Mellon FA, Foidl N, Pratt JH, Dupont MS, Perkins $\mathrm{L}$, Kroon PA. Profiling glucosinolates and phenolics in vegetative and reproductive tissues of the multi-purpose trees Moringa oleifera L. (horseradish tree) and Moringa stenopetala L. J Agric Food Chem. 2003;51(12):3546-53. https://doi.org/10.1021/jf0211480

10. Vongsak B, Sithisarn $P$, Mangmool S, Thongpraditchote $S$, Wongkrajang Y, Gritsanapan W. Maximizing total phenolics, total flavonoids contents and antioxidant activity of Moringa oleifera leaf extract by the appropriate extraction method. Ind Crops Prod. 2013;44:566-71.

https://doi.org/10.1016/j.indcrop.2012.09.021

11. Vongsak B, Gritsanapan W, Wongkrajang Y, Jantan I. In vitro inhibitory effects of Moringa oleifera leaf extract and its major components on chemiluminescence and chemotactic activity of phagocytes. Nat Prod Commun. 2013;8(11):1559-61.

12. Chumark $P$, Khunawat $P$, Sanvarinda $Y$, Phornchirasilp $S$, Morales NP, Phivthong-ngam $L$, et al. The in vitro and ex vivo antioxidant properties, hypolipidaemic and antiatherosclerotic activities of water extract of Moringa oleifera Lam. leaves. J Ethnopharmacol. 2008;116(3):439-46.

https://doi.org/10.1016/j.jep.2007.12.010

13. Verma AR, Vijayakumar M, Mathela CS, Rao CV. In vitro and in vivo antioxidant properties of different fractions of Moringa 
oleifera leaves. Food Chem Toxicol. 2009;47(9):2196-201. https://doi.org/10.1016/j.fct.2009.06.005

14. Toma A, Makonnen E, Debella A, Tesfaye B. Antihyperglycemic effect on chronic administration of butanol fraction of ethanol extract of Moringa stenopetala leaves in alloxan induced diabetic mice. Asian Pac J Trop Biomed. 2012;2(3):S1606-S1610.

https://doi.org/10.1016/S2221-1691(12)60461-4

15. Clevidence BA, Khachik F, Brown ED, Nair PP, Wiley ER, Prior $\mathrm{RL}$, et al. Human consumption of carotenoid-rich vegetables. In: Aruoma OI, Cuppett SL, editors. Antioxidant methodology: in vivo and in vitro concepts. Champaign, IL, USA: AOCS Press; 1997. pp. 53-62.

16. Atrooz OM. The antioxidant activity and polyphenolic contents of different plant seeds extracts. Pak J Biol Sci. 2009;12(15):1063-8.

https://doi.org/10.3923/pjbs.2009.1063.1068

17. Hossain M, Brunton N, Barry-Ryan C, Martin-Diana AB, Wilkinson M. Antioxidant activity of spice extracts and phenolics in comparison to synthetic antioxidants. Rasayan J Chem. 2008;1(4):751-6.

18. Sreelatha S, Padma PR. Antioxidant activity and total phenolic content of Moringa oleifera leaves in two stages of maturity. Plant Foods Hum Nutr. 2009;64:303-11. https://doi.org/10.1007/s11130-009-0141-0

19. Chemat F, Rombaut N, Sicaire AG, Meullemiestre A, Fabiano-Tixier AS, Abert-Vian M. Ultrasound assisted extraction of food and natural products. Mechanisms, techniques, combinations, protocols and applications. A review. Ultrason Sonochem. 2017;34:540-60.

https://doi.org/10.1016/j.ultsonch.2016.06.035

20. Chemat F, Zill-e-Huma, Khan MK. Applications of ultrasound in food technology: processing, preservation and extraction. Ultrason Sonochem. 2011;18(4):813-35. https://doi.org/10.1016/j.ultsonch.2010.11.023

21. Feng H, Barbosa-Cánovas GV, Weiss J, editors. Ultrasound technologies for food and bioprocessing. In: Food engineering series. New York, NY, USA: Springer; 2011.

https://doi.org/10.1007/978-1-4419-7472-3

22. Luque-García J, Luque de Castro MD. Ultrasound: a powerful tool for leaching. TrAC Trends Anal Chem. 2003;22(1):41-7. https://doi.org/10.1016/S0165-9936(03)00102-X

23. Vinatoru M. An overview of the ultrasonically assisted extraction of bioactive principles from herbs. Ultrason Sonochem. 2001;8(3):303-13.

https://doi.org/10.1016/S1350-4177(01)00071-2

24. Altemimi A, Watson DG, Choudhary R, Dasari MR, Lightfoot DA. Ultrasound assisted extraction of phenolic compounds from peaches and pumpkins. PLoS ONE. 2016;11(2):e0148758.

https://doi.org/10.1371/journal.pone.0148758
25. Albu S, Joyce E, Paniwnyk L, Lorimer JP, Mason TJ. Potential for the use of ultrasound in the extraction of antioxidants from Rosmarinus officinalis for the food and pharmaceutical industry. Ultrason Sonochem. 2004;11(3-4):261-5. https://doi.org/10.1016/j.ultsonch.2004.01.015

26. Hossain MB, Brunton NP, Patras A, Tiwari B, O'Donnell C, Martin-Diana AB, Barry-Ryan C. Optimization of ultrasound assisted extraction of antioxidant compounds from marjoram (Origanum majorana L.) using response surface methodology. Ultrason Sonochem. 2012;19(3):582-90. https://doi.org/10.1016/j.ultsonch.2011.11.001

27. Uribe E, Delgadillo A, Giovagnoli-Vicuña C, Quispe-Fuentes I, Zura-Bravo L. Extraction techniques for bioactive compounds and antioxidant capacity determination of Chilean papaya (Vasconcellea pubescens) Fruit. J Chem. 2015;2015: Article ID 347532.

https://doi.org/10.1155/2015/347532

28. Dadi DW, Emire SA, Hagos AD, Assamo FT. Influences of different drying methods and extraction solvents on total phenolic and flavonoids, and antioxidant capacity of Moringa stenopetala leaves. J Pharmacogn Phytochem. 2018;7(1):962-7.

29. Adom KK, Liu RH. Antioxidant activity of grains. J Agric Food Chem. 2002;50(21):6182-7. https://doi.org/10.1021/jf0205099

30. Brand-Williams W, Cuvelier ME, Berset C. Use of a free radical method to evaluate antioxidant activity. LWT - Food Sci Technol. 1995;28(1):25-30.

https://doi.org/10.1016/S0023-6438(95)80008-5

31. Re R, Pellegrini N, Proteggente A, Pannala A, Yang M, Rice-Evans $C$. Antioxidant activity applying an improved ABTS radical cation decolorization assay. Free Radic Biol Med. 1999;26(9-10):1231-7.

https://doi.org/10.1016/S0891-5849(98)00315-3

32. Nguyen VT, Van Vuong Q, Bowyer MC, Van Altena IA, Scarlett CJ. Effects of different drying methods on bioactive compound yield and antioxidant capacity of Phyllanthus amarus. Dry Technol. 2015;33(8):1006-17.

https://doi.org/10.1080/07373937.2015.1013197

33. Benzie IFF, Strain JJ. The ferric reducing ability of plasma (FRAP) as a measure of "antioxidant power": The FRAP assay. Anal Biochem. 1996;239(1):70-6.

https://doi.org/10.1006/abio.1996.0292

34. Chew YL, Goh JK, Lim YY. Assessment of in vitro antioxidant capacity and polyphenolic composition of selected medicinal herbs from Leguminosae family in Peninsular Malaysia. Food Chem. 2009;116(1):13-8.

https://doi.org/10.1016/j.foodchem.2009.01.091

35. IBM SPSS, v. 20.0, IBM Corp, Armonk, NY, USA; 2011. Available from https://www.ibm.com.

36. Das PR, Eun JB. A comparative study of ultra-sonication and agitation extraction techniques on bioactive metabolites of 
green tea extract. Food Chem. 2018;253:22-9.

https://doi.org/10.1016/j.foodchem.2018.01.080

37. Ahmed M, Jiang GH, Park JS, Ki Chang L, Yoon YS, Eun JB. Effects of ultrasonication, agitation and stirring extraction techniques on the physicochemical properties, health-promoting phytochemicals, and structure of cold brewed coffee. J Sci Food Agr. 2018:99(1):290-301.

https://doi.org/10.1002/jsfa.9186

38. Santos FFP, Rodrigues S, Fernandes FAN. Optimization of the production of biodiesel from soybean oil by ultrasound assisted methanolysis. Fuel Process Technol. 2009;90(2):312-6. https://doi.org/10.1016/j.fuproc.2008.09.010

39. Bernatoniene J, Cizauskaite U, Ivanauskas L, Jakstas V, Kalveniene Z, Kopustinskiene DM. Novel approaches to optimize extraction processes of ursolic, oleanolic and rosmarinic acids from Rosmarinus officinalis leaves. Ind Crops Prod. 2016;84:72-9.

https://doi.org/10.1016/j.indcrop.2016.01.031
40. Bashi DS, Mortazavi SA, Rezaei K, Rajaei A, Karimkhani MM. Optimization of ultrasound-assisted extraction of phenolic compounds from yarrow (Achillea bieberstenii) by response surface methodology. Food Sci Biotechnol. 2012;21(4):1005-11.

https://doi.org/10.1007/s10068-012-0131-0

41. Ma YQ, Chen JC, Liu DH, Ye XQ. Simultaneous extraction of phenolic compounds of citrus peel extracts: Effect of ultrasound. Ultrason Sonochem. 2009;16(1):57-62.

https://doi.org/10.1016/j.ultsonch.2008.04.012

42. Shahidi F, Yeo JD. Insoluble-bound phenolics in food. Molecules. 2016;21(9): Article no. 1216.

https://doi.org/10.3390/molecules21091216

43. Acosta-Estrada BA, Gutiérrez-Uribe JA, Serna-Saldívar SO. Bound phenolics in foods, a review. Food Chem. 2014; 152:46-55.

https://doi.org/10.1016/j.foodchem.2013.11.093 